\title{
Utilização de resíduos da construção civil na pavimentação: uma revisão sistemática
}

A indústria da construção civil é responsável por gerar enorme quantidade de resíduos. Estes resíduos de construção e demolição (RCD) poderiam ser reciclados, servindo de matéria-prima, podendo ser aplicado em vários processos construtivos, minimizando o impacto ambiental. Esta pesquisa objetiva uma revisão sistemática sobre a utilização de resíduos da construção e demolição na pavimentação Brasileira, mostrando o aproveitamento e vantagens quanto materia construtivo. Uma revisão sistemática, é uma forma de pesquisa que utiliza como fonte, dados da literatura sobre um determinado tema. As seguintes bases de periódicos foram utilizadas na busca por material: Sciello, Google Scholar, Infohab e demais sites, utilizando as palavras-chaves em português: 'resíduos sólidos + pavimentação' e 'materiais reciclados + pavimentação', visando publicações nacionais mais recentes entre o ano de 2015 a 2020 . Os resultados foram divididos quanto a aplicação dos resíduos em misturas asfálticas, camadas de base, sub-base, reforço do subleito e em intertravados. 0 resultado da pesquisa deixa claro, quanto a viabilidade do aproveitamento do RCD em atividades voltadas a pavimentação, além de apresentarem uma economia em relação ao material natural, promovem um ganho ambiental, reduzindo a extração de matéria-prima, assim como o acúmulo em aterros sanitários.

Palavras-chave: RCD; Pavimentação; Intertravados; Reciclagem; Construção civil.

\section{Use of civil construction waste in paving: a systematic review}

The construction industry is responsible for generating huge amounts of waste. This construction and demolition waste (RCD) could be recycled, serving as raw material, and can be applied in various construction processes, minimizing the environmental impact. This research aims at a systematic review on the use of construction and demolition waste in Brazilian paving, showing the use and advantages regarding construction material. A systematic review is a form of research that uses data from the literature on a given topic as a source. The following bases of journals were used in the search for material: Sciello, Google Scholar, Infohab and other sites, using the keywords in Portuguese: 'solid waste + paving' and 'recycled materials + paving', aiming at more recent national publications among the year 2015 to 2020. The results were divided as to the application of residues in asphalt mixtures, base layers, sub-base, reinforcement of the subgrade and in interlocking. The result of the research makes it clear, regarding the feasibility of using the RCD in activities aimed at paving, besides presenting an economy in relation to natural material, they promote an environmental gain, reducing the extraction of raw material, as well as the accumulation in landfills Sanitary.

Keywords: RCD; Paving; Interlocked; Recycling; Construction.

Topic: Engenharia Civil

Reviewed anonymously in the process of blind peer.

Ana Luiza Rezende de Melo

Faculdade CNEC, Brasil

http://lattes.cnpq.br/8057899499801656

almelo331@gmail.com

Marinaldo Loures Ferreira (iv)

Universidade Federal dos Vales do Jequitinhonha e Mucuri, Brasil http://lattes.cnpq.br/2795031758366655

http://orcid.org/0000-0002-8106-2793

marinaldo79@gmail.com

Reimário de Castro Rodrigues (iD

Universidade Federal dos Vales do Jequitinhonha e Mucuri, Brasil http://lattes.cnpq.br/9975393982860761

http://orcid.org/0000-0003-0829-8617

reimario.c.rodrigues@gmail.com
Received: 17/12/2020

Approved: 10/03/2021
Referencing this:

MELO, A. L. R.; FERREIRA, M. L.; RODRIGUES, R. C.. Utilização de resíduos da construção civil na pavimentação: uma revisão sistemática. Engineering Sciences, v.9, n.1, p.102-113, 2021. DOI: http://doi.org/10.6008/CBPC2318-3055.2021.001.0011 


\section{INTRODUÇÃO}

A construção civil é uma área com capacidade bem expressiva na economia do país, possui a capacidade de elevar a taxa de emprego e de renda, assim como o desenvolvimento social (OLIVEIRA, 2012; GOMES et al., 2019). Contudo, além do consumo de recursos naturais, os empreendimentos de construção geram resíduos (IPEA, 2012).

A indústria da construção civil é responsável por gerar enorme quantidade de resíduos, que acabam sendo descartados em aterros irregulares, resíduos esses que poderiam ser reciclados, minimizando o impacto ambiental (ALMEIDA et al., 2020). Estes resíduos de construção e demolição (RCD), portanto, são os entulhos provenientes das construções, reformas, reparos e demolições de obras de construção civil em geral (KIST et al., 2017).

O RCD serve de matéria-prima para agregados, podendo ser aplicado em vários processos construtivos: confecção de tijolos, blocos pré-moldados, meio-fio, calçadas, argamassa de revestimento, principalmente em pavimentos, nas camadas de base e sub-base (BRASILEIRO et al., 2015).

O pavimento é uma estrutura de múltiplas camadas de espessuras finitas, construída sobre a superfície final de terraplanagem, destinada técnica e economicamente a resistir aos esforços oriundos do tráfego de veículos e do clima, e a propiciar aos usuários melhorias nas condições de rolamento, com conforto, economia e segurança (BERNUCCl et al., 2010).

O uso de RCD em camadas dos pavimentos tem-se mostrado viável diante a disponibilidade deste material e da tecnologia de reciclagem. A utilização de agregados reciclados em pavimentos, tem mostrado que seus resultados são satisfatórios, sendo uma alternativa interessante na substituição de materiais naturais, principalmente na pavimentação de vias de baixo volume de tráfego (HORTEGAL et al., 2009).

Segundo o CONAMA n. 307 (BRASIL, 2002), no parágrafo 1 do artigo $4^{\circ}$ "os resíduos da construção civil não poderão ser dispostos em aterros de resíduos domiciliares [...]". Com isso, a reutilização dos resíduos na pavimentação acabam sendo uma opção para minimizar os impactos ambientais e trazendo a sustentabilidade.

Segundo Herrador (2012), a partir de um estudo experimental de campo, observaram que a capacidade de suporte apresentada com o uso do resíduo da construção e demolição (RDC) apresentou comportamento similar ao observado para uma estrutura com agregados convencionais.

Diante do exposto, este trabalho tem como objetivo realizar uma revisão sistemática sobre a utilização de resíduos da construção e demolição na pavimentação Brasileira, mostrando o aproveitamento e vantagens quanto material construtivo.

\section{REVISÃO TEÓRICA}

\section{Malha viária Brasileira}

Segundo dados da Confederação Nacional de Transporte (CNT, 2019), a malha rodoviária atual do Brasil possui uma extensão de $1.720 .700 \mathrm{~km}$, contudo, desse total, apenas $213.453 \mathrm{~km}$ são pavimentados, 
que representa em torno de $12,4 \%$, as vias não pavimentadas somam $1.349 .938 \mathrm{~km}$, correspondendo a $78,5 \%$ e $157.309 \mathrm{~km}$ planejadas, sendo 9,1\%.

Ainda de acordo com os dados da CNT (2019), das rodovias pavimentadas 30,6\% (65.370km) são federais e $69,4 \%(148.083 \mathrm{~km})$ são estaduais, transitórias, estaduais e municipais. Das federais 10,6\% (6.932km) são duplicadas, 1,8\% (1.163km) em duplicação e 87,6\% $(57.275 \mathrm{~km})$ são de pista simples.

\section{Pavimentação}

\section{Estrutura do pavimento}

Pavimento é o conjunto das camadas, cujo maior objetivo de sua vida útil é suportar o tráfego de veículos, portanto, é uma estrutura não perene, composta por camadas sobrepostas de materiais compactados de diferentes granulometrias, sendo considerada a partir do subleito de um corpo estradal, devendo ser adequada para atender estrutural e operacional ao tráfego a qual é projetada (BALBO, 2007).

Segundo o DNIT (2006), Pavimento (figura 1) é construído após a terraplanagem e destinada a resistir a distribuir ao subleito os esforços verticais oriundos do tráfego, melhorar as condições de rolamento quanto à comodidade e conforto, resistindo aos esforços horizontais, tornando mais durável a superfície de rolamento. É composto por um conjunto de camadas, com finalidades especificas, que podem ser denominadas como: Camada de Revestimento (CR), Base (B), Sub-base (SB) e Reforço do Subleito (Ref.) (SILVA, 2008).

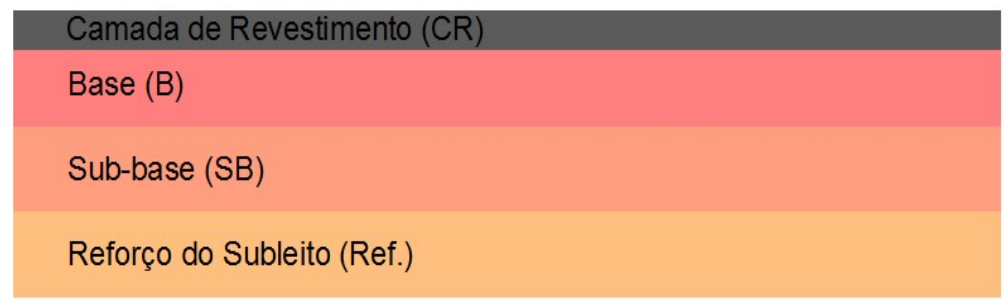

Figura 1: Pavimento. Fonte: Adaptado de Silva (2008).

Subleito refere-se ao maciço de terra que serve de fundação para o pavimento ou revestimento (DNIT, 2017). Reforço de subleito é a camada granular do pavimento executada com o objetivo de melhorar a capacidade de suporte de carga do subleito e promover a redução da espessura da sub-base (DNIT, 2017). Portanto, é uma camada construída acima da regularização do subleito quando há a necessidade, e possui características tecnológicas superiores às da regularização e inferiores às da camada imediatamente superior (SENÇO, 2007).

A camada de Sub-Base tem a finalidade de reduzir a espessura da base, proteger o subleito (SILVA, 2008). Portanto, a Sub-Base é a camada complementar à base, quando, por circunstâncias técnicas e econômicas, não for aconselhável construir a base diretamente sobre a regularização ou reforço do subleito, o material aplicado para execução da sub-base tecnicamente, deverá ter características tecnológicas superiores às do material de reforço que por sua vez, o material da base terá qualidade superior ao material da sub-base (SENÇO, 2007). 
A Base é a camada destinada a resistir aos esforços verticais oriundos dos veículos (DNIT, 2017). É a estrutura do pavimento situada acima da sub-base quando existente, ou diretamente sobre o subleito, sendo sua função principal o suporte estrutural, promovendo a rigidez e a resistência à fadiga da estrutura, para isso, os materiais aplicados exigem uma especificação rigorosa em termos de resistência, plasticidade, graduação e durabilidade (PINTO et al., 2002).

Revestimento refere-se a camada mais acima do pavimento, que recebe diretamente as ações verticais e horizontais dos veículos, e destinada a melhorar as condições do rolamento quanto ao conforto e segurança (DNIT, 2017). A camada de revestimento tem a finalidade de impermeabilizar o pavimento, aumentar a resistência a derrapagem e resistir aos esforços causados pelo trafego e pelo intemperismo, para tal exigências, podem ser usados para sua construção o Concreto de Cimento Portland (C.C.P.) ou Concreto Betuminoso Usinado a Quente (C.B.U.Q.) ou Stone Mastigue Asphalt (S.M.A.), para trafego pesado, e o PréMisturado a Quente (P.M.Q.), para tráfego leve, além destes revestimentos a quente, pode-se usar o PréMisturado a Frio (P.M.F.). Nos acostamentos podem-se usar o (T.S.S.) Tratamento Superficial Simples, enquanto que para trafego médio ou leve tem se a opção do uso do Tratamento Superficial Duplo (T.S.D) e o Tratamento Superficial Triplo (T.S.T.) (SILVA, 2008).

\section{Classificação dos Pavimentos}

O Pavimento é uma estrutura constituída de diversas camadas, que pode ser executado com várias configurações diferentes, isso em função da necessidade técnica que o projeto exigir. De uma forma geral podem ser classificados como Flexíveis, Rígidos e Semirrígidos (SENÇO, 2007).

\section{Pavimento flexível}

Os Pavimentos Flexíveis são aqueles em que todas as camadas sofrem deformação elástica significativa sob o carregamento aplicado, dessa forma a pressão se distribui entre as camadas (DNIT, 2006). O Pavimento Flexível (figura 2) é aquele em que a Camada de Revestimento é de asfalto (CA), a Base sendo executada de material granular (BG) e a Sub-base de material granular ou solo (SILVA, 2008).

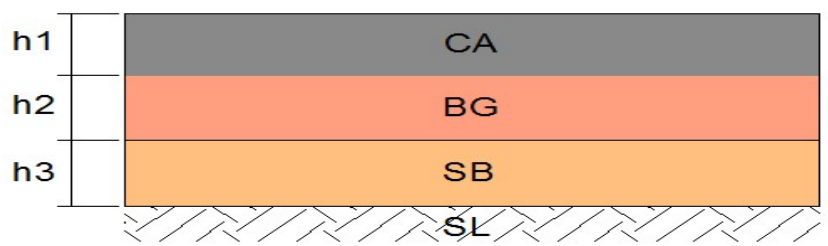

Figura 2: Pavimento Flexível. Fonte: Adaptado de Silva (2008).

\section{Pavimento Semirrígido}

Segundo o DNIT (2006) pavimento semirrígido é, "caracteriza-se por uma base cimentada por algum aglutinante com propriedades cimentícias como por exemplo, por uma camada de solo cimento revestida por uma camada asfáltica".

O que caracteriza o Pavimento Semirrígido (figura 3) é sua composição, onde a Camada de 
Revestimento é de asfalto, possui uma Base de material cimentício e uma Sub-Base de solo ou material granular. Deverá ter resistência axial mínima de 4,6 Mpa na sua Base cimentada, para evitar ruptura precoce (SILVA, 2008).

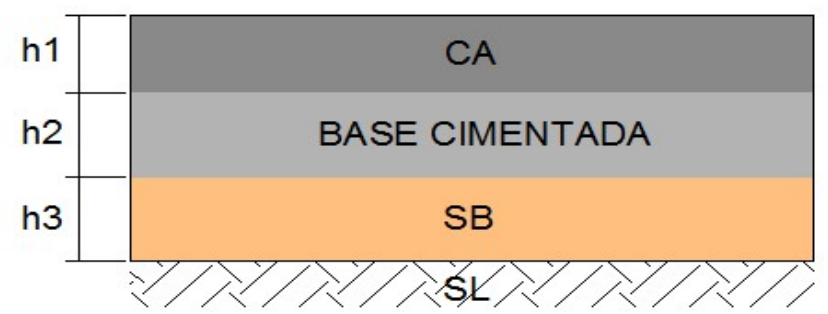

Figura 3: Pavimento Semirrígido. Adaptado de Silva (2008).

\section{Pavimento rígido}

Os Pavimentos Rígidos (figura 4) são aqueles com maior resistência a deformação, o revestimento tem uma elevada rigidez em relação às camadas inferiores e, portanto, absorve praticamente todas as tensões provenientes do carregamento aplicado (DNIT, 2006). São constituídos principalmente de concreto de cimento Portland e tendem a romper por tração na flexão, quando sujeitos a deformações (SENÇO, 2007).

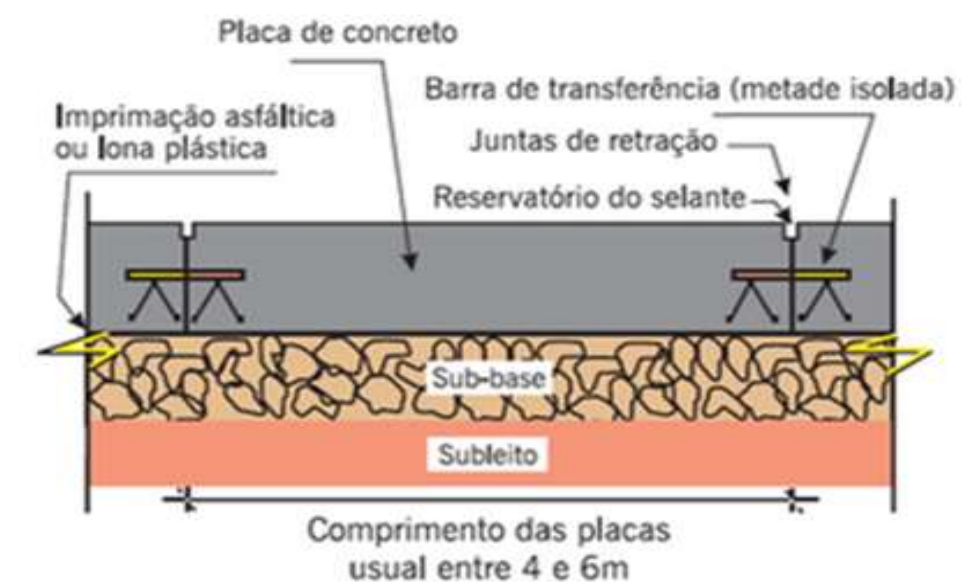

Figura 4: Estrutura do pavimento rígido. Fonte: Bernucci et al. (2010).

\section{Materiais reciclados aplicados na pavimentação}

Os materiais aplicados na pavimentação, são os RDC (figura 5) que são definidos como classe "A" referentes à Resolução Conama n³07/2002 e os materiais inclusos são tijolos, blocos cerâmicos, concreto em geral, argamassas, telhas, agregados pétreos e outros, sendo adequados para à execução de camada de reforço do subleito, sub-base e base, bem como camada de revestimento primária (NBR 15115, 2004).

A obtenção desse material, se dá por meio da britagem ou beneficiamento mecânico dos RDC e o transforma em material granular. Os materiais devem atender aos seguintes requisitos: não pode haver a presença de madeiras, vidros, plásticos, gessos, forros, tubulações, fiações elétricas e papéis ou quaisquer matérias orgânicas ou não inerentes, que pela Resolução CONAMA n 307, se classificam como classe "B", “C" e "D" (NBR 15115, 2004). 


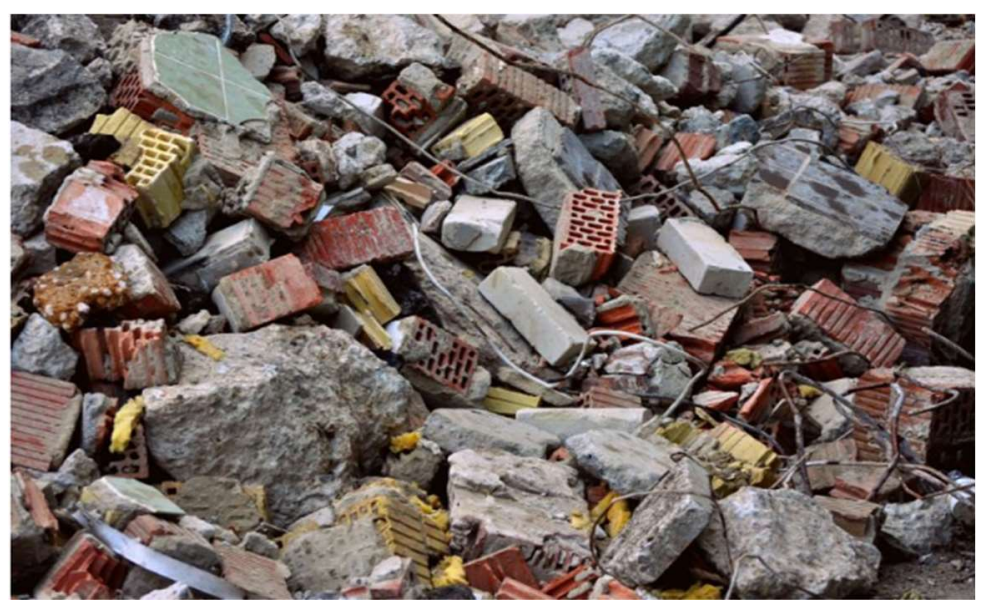

Figura 5: Resíduos da Construção e Demolição ou Resíduos da Construção Civil.

As vantagens de utilizar os RDC são que para reciclar exige uma menor utilização de tecnologia, que implica em um menor custo do processo; não tem a necessidade da separação para a utilização; existe uma economia de energia no processo da moagem e maior eficiência do resíduo quando adicionado aos solos saprolíticos em relação a mesma adição feita com brita.

Enquanto a adição de $20 \%$ de entulho reciclado ao solo saprolítico gera um aumento de $100 \%$ do CBR, nas adições de brita natural o aumento do CBR só é perceptível com dosagens a partir de $40 \%$ (ABRECON, 2020).

\section{Legislação sobre aplicação de materiais reciclados na pavimentação}

O instrumento legal que dispõe sobre a gestão e o gerenciamento dos Resíduos provenientes da construção civil no Brasil é a Resolução no 307/2002 do Conselho Nacional do Meio Ambiente - Conama. Alterada por resoluções posteriores que atualizaram a classificação e as responsabilidades sobre os RDC: Resolução Conama no 348/2004, inclui o amianto como resíduo perigoso Classe D; Resolução Conama no 431/2011, inclui o gesso como resíduo reciclável Classe B; Resolução Conama no 448/2012, atualiza os conceitos e responsabilidades em acordo com as diretrizes da Lei 12.305/2010, Política Nacional de Resíduos Sólidos - PNRS; Resolução Conama no 469/2015, inclui as embalagens de tintas imobiliárias como resíduos recicláveis Classe B (HENDGES, 2016).

Portanto, em seu Artigo 3ำ, a Resolução Conama no 307/2002, propõe a classificação dos resíduos da construção civil, que deverão seguir a seguinte divisão:

I - Classe A - são os resíduos reutilizáveis ou recicláveis como agregados, tais como:

a) de construção, demolição, reformas e reparos de pavimentação e de outras obras de infraestrutura, inclusive solos provenientes de terraplanagem;

b) de construção, demolição, reformas e reparos de edificações: componentes cerâmicos (tijolos, blocos, telhas, placas de revestimento etc.), argamassa e concreto;

c) de processo de fabricação e/ou demolição de peças pré-moldadas em concreto (blocos, tubos, meio-fio, etc.) produzidas nos canteiros de obras;

II - Classe B - são os resíduos recicláveis para outras destinações, tais como plásticos, papel, papelão, metais, vidros, madeiras, embalagens vazias de tintas imobiliárias e gesso;

III - Classe C - são os resíduos para os quais não foram desenvolvidas tecnologias ou aplicações economicamente viáveis que permitam a sua reciclagem ou recuperação; 
IV - Classe D - são resíduos perigosos oriundos do processo de construção, tais como tintas, solventes, óleos e outros ou aqueles contaminados ou prejudiciais à saúde oriundos de demolições, reformas e reparos de clínicas radiológicas, instalações industriais e outros, bem como telhas e demais objetos e materiais que contenham amianto ou outros produtos nocivos à saúde.

A Resolução Conama № 307/2002 é considerada como o principal marco regulatório para a gestão dos RDC, onde estabelece diretrizes, critérios e procedimentos, ademais, dispõe sobre a responsabilidades dos municípios em implementarem seus planos de gerenciamento integrado de RDC, bem como, diretrizes, critérios e procedimentos para o manejo adequado destes resíduos (IPEA, 2012).

Corroborando com essa resolução, a Lei 12.305 de 02 de agosto de 2010, instituiu a Política Nacional de Resíduos Sólidos, dispondo de princípios, objetivos, instrumentos, diretrizes, metas e ações, visando o gerenciamento ambiental adequado de resíduos sólidos. Além disso, atribuiu a responsabilidade dos geradores de resíduos e do poder público (BRASIL, 2010).

Respeitando as orientações da Resolução Conama no 307/2002, a Associação Brasileira de Normas Técnicas - ABNT, desenvolveu uma série de normas relativas aos resíduos sólidos (quadro 1), abordando procedimentos para o gerenciamento e aplicação dos RDC.

Quadro 1: Normas técnicas brasileiras relacionadas aos resíduos sólidos e aos RCD.

\begin{tabular}{|l|l|}
\hline Norma & Descrição \\
\hline NBR 10.004/2004 & Resíduos sólidos - Classificação \\
\hline NBR 15.112/2004 & $\begin{array}{l}\text { Resíduos da construção civil e resíduos volumosos - Áreas de transbordo e triagem - Diretrizes para projeto, } \\
\text { implantação e operação }\end{array}$ \\
\hline NBR 15.113/2004 & $\begin{array}{l}\text { Resíduos sólidos da construção civil e resíduos inertes - Aterros - Diretrizes para projeto, implantação e } \\
\text { operação }\end{array}$ \\
\hline NBR 15.114/2004 & Resíduos sólidos da Construção civil - Áreas de reciclagem - Diretrizes para projeto, implantação e operação \\
\hline NBR 15.115/2004 & $\begin{array}{l}\text { Agregados reciclados de resíduos sólidos da construção civil - Execução de camadas de pavimentação - } \\
\text { Procedimentos }\end{array}$ \\
\hline NBR 15.116/2004 & $\begin{array}{l}\text { Agregados reciclados de resíduos sólidos da construção civil - Utilização em pavimentação e preparo de } \\
\text { concreto sem função estrutural - Requisitos }\end{array}$ \\
\hline
\end{tabular}

\section{METODOLOGIA}

A metodologia adotada neste estudo é apresentada no fluxograma (Figura 6), onde contempla todas as etapas de desenvolvimento proposto.

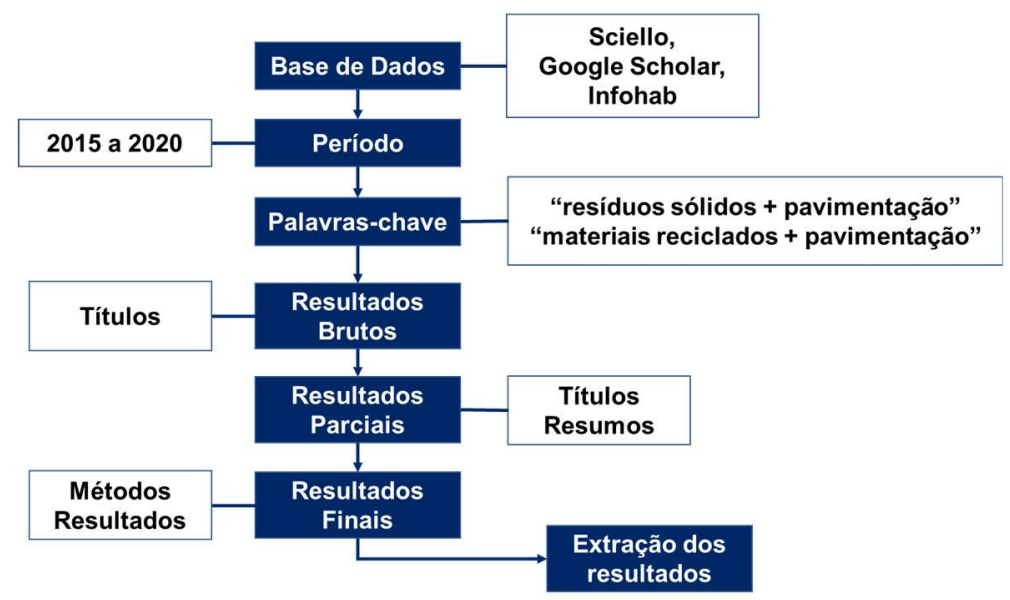

Figura 6: Fluxo metodológico.

Este estudo é uma pesquisa de natureza aplicada com objetivos de caráter exploratório (GIL, 2002), 
fazendo um levantamento quantitativo e qualitativo sobre a utilização de resíduos da construção e demolição na pavimentação Brasileira. O levantamento das publicações seguirá o método de revisão sistemática de literatura.

Uma revisão sistemática, é uma forma de pesquisa que utiliza como fonte, dados da literatura sobre um determinado tema. Esse tipo de investigação disponibiliza um resumo das evidências relacionadas a uma estratégia de intervenção específica, mediante a aplicação de métodos explícitos e sistematizados de busca, visando uma apreciação crítica e elaborando uma síntese da informação selecionada (SAMPAIO et al., 2007).

\section{Fonte de dados e palavras-chaves}

Os artigos que compuseram a pesquisa foram selecionados nas seguintes bases de periódicos: Sciello, Google Scholar, Infohab e demais sites de buscas. Nestas bases foram utilizadas as palavras-chaves em português: resíduos sólidos, materiais reciclados e pavimentação, visando publicações nacionais de 2015 a 2020. A pesquisa foi realizada utilizando um conjunto de palavras-chave, as quais foram: 'resíduos sólidos + pavimentação' e 'materiais reciclados + pavimentação'. Obteve-se um total 132 resultados selecionados nas bases citadas.

Os 132 artigos foram selecionados por meio da leitura dos seus títulos e posterior pelos resumos, visando a identificação dos estudos que englobassem a utilização dos resíduos da construção civil aplicado na pavimentação asfáltica.

Após a leitura dos resumos referentes aos 132 artigos, foram selecionados 33 estudos que apresentavam as características condizentes com a abordagem da pesquisa. Posteriormente foi realizada a leitura destes 33 estudos e identificados os artigos que realmente abordavam especificamente o objetivo da pesquisa. Portanto, resultou-se em 10 artigos, que foram utilizados para a construção final desta investigação.

\section{RESULTADOS E DISCUSSÃO}

A partir da pesquisa realizada descreveu-se sobre os resultados obtidos quanto a utilização dos resíduos de construção civil aplicado na pavimentação. Os resultados foram divididos quanto a aplicação dos resíduos em misturas asfálticas, camadas de base, sub-base, reforço do subleito e em intertravados.

\section{Mistura asfáltica}

Queiroz Neto et al. (2020) avaliaram um trecho experimental de revestimento asfáltico com o uso do $R C D$, observando que os agregados oriundos de RCD desempenharam um bom potencial de sua utilização em revestimentos asfálticos à quente, baseado nas análises dos corpos de prova. Concluíram em seu estudo, que o RCD para uso em pavimentação asfáltica, possuem boas propriedades referentes a Abrasão Los Angeles $(35 \%)$ e índice de forma $(0,87)$ atendendo os parâmetros estabelecidos pelas normas (ABNT) vigentes.

O uso do seixo como agregado na mistura asfáltica a quente, tem uma grande vantagem em relação 
a sua elevada resistência mecânica, mas o que faz o RCD ser utilizado é que minimiza o impacto nos rios como poluição por combustíveis, morte de vida aquática, o desmatamento na área do material extraído, entre outros, evitando a retirada do seixo (BRASILEIRO et al., 2015).

Segundo Oliveira (2012) além do uso do RCD ser uma ótima opção pela parte ecológica, um outro ponto positivo é que não apresentou grandes deformações na camada de base e, consequentemente, no pavimento quando houve contato com a água e também há um aumento na resistência a compressão.

O uso do agregado reciclado apresenta resultados e características satisfatórias cumprindo as especificações da NBR 15115, assim podendo ser utilizado em camadas de pavimento. $O$ incentivo do uso do agregado reciclado se dá também pelo seu preço inferior aos materiais convencionais e ainda proporciona uma destinação adequada para os RCD (KIST et al., 2017).

\section{Camadas de base, sub-base e reforço do subleito}

Silveira et al. (2016) analisou amostras onde o RCC foi utilizado como agregado miúdo, avaliando três amostras, sendo a primeira amostra com $100 \%$ de solo, a segunda amostra continha $70 \%$ de solo $+30 \%$ de RCC e a terceira continha $50 \%$ de solo $+50 \%$ de RCC. Os resultados de Índice de Suporte Califórnia (ISC) foram de: ISC=10,9\% e expansão de 0,64\% na amostra 1; ISC=14,5\% e expansão de 0,13\% na amostra 2; e, ISC $=20,43 \%$ e expansão de $0,08 \%$ na amostra 3 . Concluíram, portanto, que a amostra 2 poderia ser utilizada em camada de subleito e a amostra 3 em sub-base de pavimento.

Santos et al. (2015) analisaram duas misturas com o RCD, sendo elas, a mistura $1 \mathrm{com} 44 \%$ de solo + $56 \%$ de agregado reciclado e a mistura 2 com $17 \%$ de solo $+83 \%$ de agregado reciclado, também analisou o agregado reciclado puro e o solo. Obtendo resultados satisfatórios, onde as misturas 1 e 2 poderiam ser utilizadas como sub-base e o agregado reciclado puro como tem uma resistência elevada à penetração, poderia ser utilizado como camada de base de pavimento. Os autores, enfatizam que a estrutura de pavimento que foi proposta geraria uma redução de $8,8 \%$ no custo financeiro da construção.

A capacidade do RCD em substituir os agregados naturais que são usados na pavimentação, especificamente na base de pavimentos são satisfatórias, os resultados laboratoriais confirmam esse uso, e também mostram que a utilização desse material interfere nitidamente no orçamento, que chega a ter uma economia de 56,67\% em relação ao material natural (SANTOS et al., 2019).

\section{Intertravados}

Os intertravados ou Pavers, são peças de concreto para pavimentação ou calçamentos, sendo peças pré-moldadas de concreto, cuja transmissão de parte da carga entre as peças, se dá através do atrito lateral entre elas (ABNT NBR 9781/2013).

Morais et al. (2018) avaliaram amostras de resíduos da construção civil aplicados na confecção de pavers, constatando, que as amostras produzidas unicamente com agregados reciclados, apresentaram maiores índices de absorção em relação aos outros traços, 0,13 \% abaixo do limite normatizado e resistência mecânica 30 \% menor que o traço produzido com agregados naturais. Os autores, enfatizam que devido ao 
menor custo de produção em relação aos demais, mesmo os traços que não atendem a norma quanto a resistência, podem-se ser utilizados em locais sem fins estruturais como, por exemplo, calçadas e jardins.

Augusto Junior et al. (2017) avaliaram blocos sextavados de concreto, cujo traço, com Teor de 60\% de agregados miúdos reciclados. Obtendo resistências médias finais de compressão na idade de 28 dias, entorno de 43,28, atendendo ao mínimo de $35 \mathrm{MPa}$ ditado pela norma. Os autores atestam que é tecnicamente viável a incorporação de agregados miúdos reciclados a partir do beneficiamento de resíduos de concreto e cerâmico ao traço para a confecção de peças pré-moldadas para pavimentação intertravada.

A confecção de pavers aparece como uma solução ao uso dos reciclados da construção civil, reforçado pela pesquisa de Dantas Filho et al. (2020), onde as substituições do agregado natural por RCC foram nas proporções de $10 \%, 20 \%, 30 \%, 40 \%$ e $50 \%$, o qual, todos os traços apresentaram resistência à compressão sendo superiores a $35 \mathrm{MPa}$ e absorção inferior a 6\% mencionado na norma.

Carvalho et al. (2018) foram mais categóricos, realizaram testes com substituição parcial e total de agregados graúdos e miúdos, nas proporções de $20 \%, 40 \%, 60 \%, 80 \%$ e $100 \%$, constatando que referente aos quesitos técnicos, ambientais e econômicos, fica evidenciado que o melhor índice de substituição é o de 100\% de agregado reciclado, apresentando valores de resistência de 38,2 MPa para agregados miúdos e 37,7 MPa para agregados graúdos.

\section{CONCLUSÕES}

Diante dos aspectos apresentados, conclui-se que os agregados provenientes do RCD, além de apresentarem uma economia em relação ao material natural, promovem um ganho ambiental, reduzindo a extração de matéria-prima, assim como o acúmulo em aterros sanitários.

O resultado da pesquisa deixa claro, quanto a viabilidade do aproveitamento do RCD em atividades voltadas a pavimentação, podendo ser aplicado na mistura asfáltica, na composição de base e sub-base, assim como, em intertravados, atendendo no que tange as normas vigentes, contribuindo para a quebra de paradigmas e bloqueios estabelecidos frente ao emprego desses insumos.

Observa-se, que o RCD para ser utilizado em substituição a materiais usuais em pavimentação, fazse necessário que tais resíduos sejam reciclados de forma coerente, devendo ser previamente selecionados e classificados conforme seu uso final, sendo necessário testes laboratoriais que comprovem suas características quanto material construtivo.

Esta pesquisa evidencia o potencial gerador de resíduos da construção civil, assim como a importância em reciclar de forma controlada esses materiais. O poder público possui ferramentas eficientes para gestão destes resíduos, apesar de não ser um processo simples, portanto, percebe-se, a falta de uma política mais efetiva envolvendo todos os setores, onde uma parceria, poderia instalar britadores para usinas de reciclagem especificas para RCD, podendo atender os órgãos públicos, seja na elaboração e manutenção da pavimentação urbana quanto rural. 


\section{REFERÊNCIAS}

ALMEIDA, E. G.; MUNIZ, J. S.; AMORIM, M. S.; JUNIOR, J. R. L. P.; ALENCAR, D. B.; PARENTE, R. S.. Logística reversa como proposta de melhoria em uma empresa de construção civil situada na capital do Amazonas. South American Development Society Journal, v.06, n.16, 2020. DOI: http://doi.org/10.24325/issn.2446-5763.v6i16p125-141

ABNT. Associação Brasileira de Normas Técnicas. NBR 15112: Resíduos da construção civil e resíduos volumosos Áreas de transbordo e triagem - Diretrizes para projeto, implantação e operação. Rio de Janeiro: ABNT, 2004.

ABNT. Associação Brasileira de Normas Técnicas. NBR 15113: Resíduos sólidos da construção civil e resíduos inertes - Aterros - Diretrizes para projeto, implantação e operação. Rio de Janeiro: ABNT, 2004.

ABNT. Associação Brasileira de Normas Técnicas. NBR 15114: Resíduos sólidos da construção civil - Áreas de reciclagem - Diretrizes para projeto, implantação e operação. Rio de Janeiro: ABNT, 2004.

ABNT. Associação Brasileira de Normas Técnicas. NBR 15115: Agregados reciclados de resíduos sólidos da construção civil - Execução de camadas de pavimentação Procedimentos. Rio de Janeiro: ABNT, 2004.

ABNT. Associação Brasileira de Normas Técnicas. NBR 15116: Agregados reciclados de resíduos sólidos da construção civil - Utilização em pavimentação e preparo de concreto sem função estrutural - Requisitos. Rio de Janeiro: ABNT, 2004.

ABNT. Associação Brasileira de Normas Técnicas. NBR 9781: Peças de concreto para pavimentação - Especificação e métodos de ensaios. Rio de Janeiro: ABNT, 2013.

ABRECON. Associação Brasileira para Reciclagem de Resíduos da Construção Civil e Demolição. Utilização na Pavimentação. São Paulo: ABRECON, 2020.

AUGUSTO JUNIOR, J.; FRANCISCO, J. T. M.; DIAS, A. B.; GONÇALVES, I. B. G.; ALTRAN, D. A.; FIGUEIREDO, F. B. Estudo das propriedades de blocos sextavados de concreto para pavimentação com uso de resíduos de construção civil. Colloquium Exactarum, v.9, n.2, p.65-76, 2017. DOI: http://doi.org/10.5747/ce.2017.v09.n2.e194

BALBO, J. T.. Pavimentação asfáltica: materiais, projetos e restauração. São Paulo: Oficina de Textos, 2007.

BERNUCCI, L. B.; MOTTA, L. M. G.; CERATTI, J. A. P.; SOARES, J. B.. Pavimentação Asfáltica: formação básica para engenheiros. 3 ed. Rio de Janeiro: Imprinta, 2010.

BRASIL. Lei n. 12.305, de 02 de agosto de 2010. Institui a Política Nacional de Resíduos Sólidos. Brasília: DOU, 2010.

BRASIL. Ministério do Meio Ambiente. Resolução Conama n. 307, de 5 de julho de 2002. Estabelece diretrizes, critérios e procedimentos para a gestão dos resíduos da construção civil. Brasília: DOU, 2002.

BRASILEIRO, L. L.; MATOS, J. M. E.. Revisão bibliográfica: reutilização de resíduos da construção e demolição na indústria da construção civil. Cerâmica, v.61, n.358, 2015. DOI: http://doi.org/10.1590/0366-69132015613581860

CARVALHO, R. A.; MORAES, A. C. Z.; MIZASSE, B. R.; NETO, M. F.. Utilização de resíduos de corpos de prova de concreto para fabricação de pavimentação intertravada. Revista InterScientia, v.6, n.2, p.12-29, 2018. DOI: http://doi.org/doi.org/10.26843/interscientia.v6i2.872

CNT. Confederação Nacional do Transporte. Pesquisa CNT de Rodovias 2019. Serviço Nacional de Aprendizagem do Transporte. Brasília: CNT, 2019.

DNIT. Departamento Nacional de Infraestrutura de Transporte. Glossário de Termos Técnicos Rodoviários. Instituto de Pesquisas Rodoviárias. Rio de Janeiro: DNIT, 2017.

DNIT. Departamento Nacional de Infraestrutura de Transporte. Manual de Pavimentação Rodoviária. Instituto de Pesquisas Rodoviárias. Rio de Janeiro: DNIT, 2006.

DANTAS FILHO, M. D.; BADÚ, A. M. F.; SILVA, F. D. G.; GUEDES, S. B.; MAIA, Y. W. A.. Estudo do concreto com RCC para produção de pavers para pavimentação no campus UFCG-Pombal. In: CONRESUL, 3. Anais. Gramado: IBEAS, 2020. p.1-9.

GIL, A. C.. Como elaborar projetos de pesquisa. 4 ed. São Paulo: Atlas, 2002.

GOMES, B.; SILVA, D. A.. Construção civil: importância do planejamento de obras construction. Revista Científica Semana Acadêmica, v.1, n.158, p.1-18, 2019.

HENDGES, A. S.. Gestão e gerenciamento de resíduos da construção civil. 2016.

HERRADOR, R.; PÉREZ, P.; GARACH, L.; ORDÓÑEZ, J.. Use of Recycled Construction and Demolition Waste Aggregate for Road Course Surfacing. Journal of Transportation Engineering, v.138, p.182-190, 2012.

HORTEGAL, M. V.; FERREIRA, T. C.; SANT'ANA, W. C.. Utilização de agregados resíduos sólidos da construção civil para pavimentação em São Luís - MA. Pesquisa em Foco, v.17, n.2, p.60-74, 2009.

IPEA. Instituto de Pesquisa Econômica Aplicada. Diagnóstico dos Resíduos Sólidos da Construção Civil: relatório de pesquisa. Brasília: IPEA, 2012.

KIST, K. J.; BARTH, A. A.; LIMANA, L.; REICHERT, L. S.. O uso de resíduos de construção e demolição (RCD) como substituição da matéria prima natural em base, sub-base e subleito de pavimentações. In: CONGRESSO REGIONAL DE INICIAÇÃO CIENTÍFICA E TECNOLÓGICA EM ENGENHARIA, 28. Anais. CRICTE, 2017.

OLIVEIRA, V. F.. O papel da indústria civil na organização do espaço e do desenvolvimento regional. In: CONGRESSO INTERNACIONAL DE COOPERAÇÃO UNIVERSIDADEINDÚSTRIA. Anais. Taubaté, 2012. 
PINTO, S.; PREUSSLER, E. W.. Pavimentação rodoviária: conceitos fundamentais sobre pavimentos flexíveis. Rio de Janeiro, 2002.

QUEIROZ NETO, M. L.; AMORIM, E. F.; FRANÇA, F. A. N.; MEDEIROS, M. K. S.. Evaluation of an experimental hot asphalt concrete urban paving section using construction and works demolition waste (CDW) as a coating layer. J. Environ. Manag. \& Sust., v.9, n.1, p.1-18, 2020. DOI: http://doi.org/10.5585/geas.v9i1.16108

SAMPAIO, R. F.; MANCINI, M. C.. Estudos de revisão sistemática: um guia para síntese criteriosa da evidência científica. Revista Brasileira de Fisioterapia, São Carlos, v.11, n.1, p.83-89, 2007.

SANTOS, A. G.; TEIXEIRA, R. W.; MELLO, E. A.; TEIXEIRA, J.. Avaliação do custo de construção de uma estrutura de pavimento empregando agregado reciclado de rcd. REEC: Revista Eletrônica de Engenharia Civil, v.10, n.1, p.1-13, 2015. DOI: http://doi.org/10.5216/reec.v10i1.31557

SANTOS, J. O.; ARAÚJO, C. B. C.; AYRES, T. M. C.. Análise da utilização de RCD em obras de pavimentação na cidade de Fortaleza. v.5, p.65-72, 2019.

SENÇO, W.. Manual de técnicas de pavimentação. 2 ed. São Paulo: Pini, 2007.

SILVA, P. F. A.. Manual de patologia e manutenção de pavimentos. 2 ed. São Paulo: Pini, 2008.

SILVEIRA, L. R.; BORGES, R. A.. Análise do uso de resíduos da construção civil como agregado miúdo em pavimentação. RENEFARA: Revista Eletrônica de Educação da UniAraguaia Centro Universitário, p.112-122, 2016.

A CBPC - Companhia Brasileira de Produção Científica (CNPJ: 11.221.422/0001-03) detém os direitos materiais desta publicação. Os direitos referem-se à publicação do trabalho em qualquer parte do mundo, incluindo os direitos às renovações, expansões e disseminações da contribuição, bem como outros direitos subsidiários. Todos os trabalhos publicados eletronicamente poderão posteriormente ser publicados em coletâneas impressas sob coordenação da Sustenere Publishing, da Companhia Brasileira de Produção Científica e seus parceiros autorizados. Os (as) autores (as) preservam os direitos autorais, mas não têm permissão para a publicação da contribuição em outro meio, impresso ou digital, em português ou em tradução. 